Document downloaded from:

http://hdl.handle.net/10251/123508

This paper must be cited as:

Guardiola, C.; Pla Moreno, B.; Real-Minuesa, M.; Travaillard, C.; Dambricourt, F. (2018). Short-circuit effects on spark ignition engine after-treatment and fuel-to-air ratio control. International Journal of Engine Research. https://doi.org/10.1177/1468087418796705

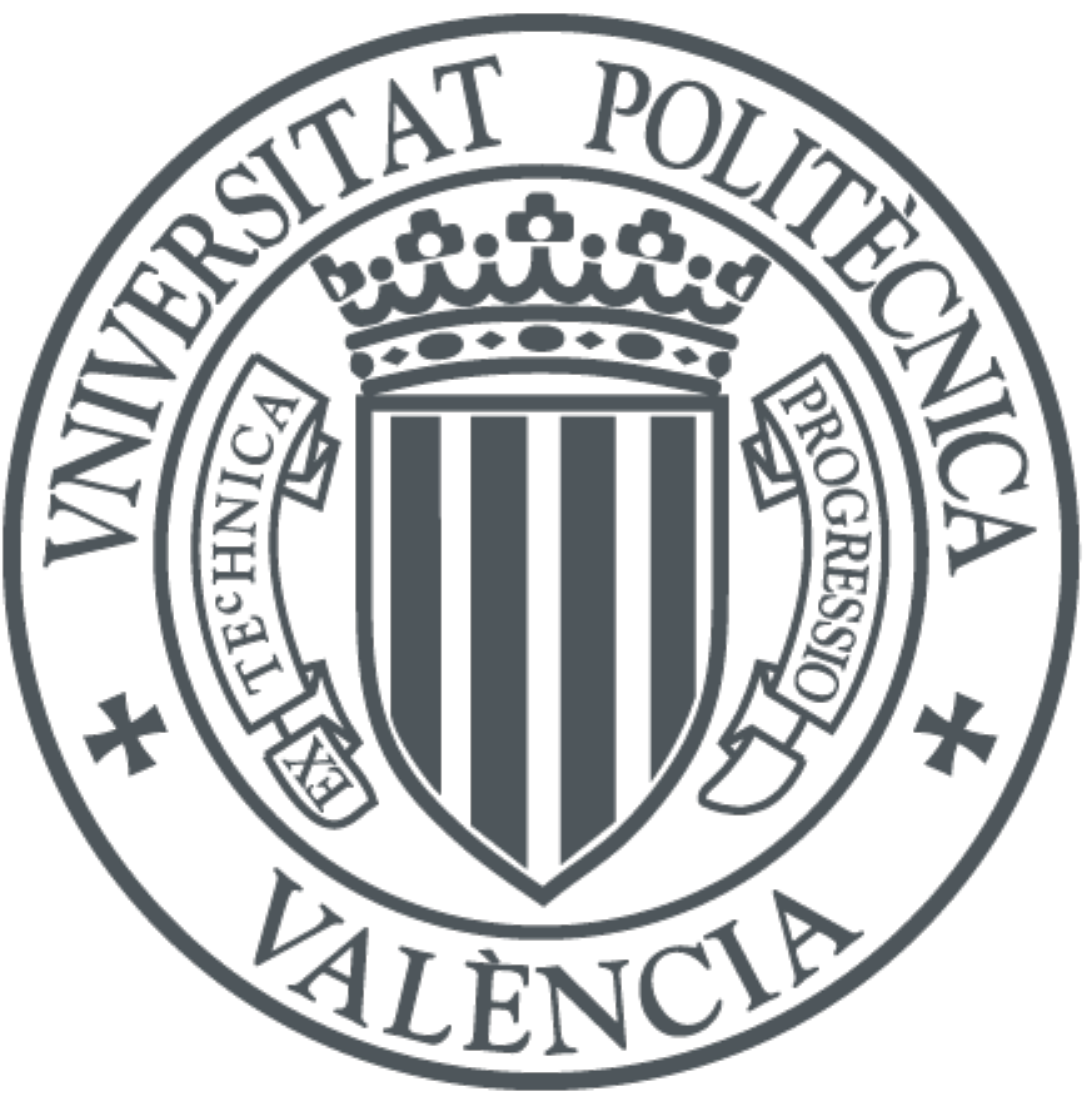

The final publication is available at

https://doi.org/10.1177/1468087418796705

Copyright SAGE Publications

Additional Information 


\title{
Short-circuit effects on spark ignition engine after-treatment and fuel-to-air ratio control
}

\author{
Carlos GUARDIOLA ${ }^{1}$, Benjamín PLA ${ }^{1}$, Marcelo REAL ${ }^{1}$, Cyril TRAVAILLARD ${ }^{2}$ and Frederic \\ DAMBRICOURT $^{2}$
}

\begin{abstract}
The short-circuit (SC) of fresh air is a more and more extended strategy to deal with low-end torque issues, very common in small turbocharged and spark ignited four-stroke engines. Therefore, from the author's point of view, it is interesting to check whether the after-treatment system can work properly under these conditions. In the present study, the effect of the fresh air SC on engine emissions has been assessed through its impact on the wideband $\lambda$ sensor and the three-way catalyst (TWC) behaviour, which are the key elements of the fuel-to-air ratio (FAR) control strategy. In particular, the analysis of the sensor dynamic response shows that the $\lambda$ sensor overestimates the FAR under SC conditions. The sensor overestimation leads the actual FAR out of the proper TWC window, in this sense, results show a non-negligible emissions increase, especially in terms of $\mathrm{NO}_{\mathrm{x}}$. Regarding the impact on the TWC behaviour, the study shows how SC pulses change the exhaust gas composition for a given FAR at catalyst inlet, which also contributes to a penalty in the TWC efficiency.
\end{abstract}

\section{Keywords}

Spark ignited engine, Fuel-to-air ratio control, Three-way catalyst, Short-circuit, Emissions control

\section{Introduction}

During last years, with turbocharging popularization, the short-circuit (SC) of fresh air ${ }^{1}$ is becoming an essential approach to solve the typical low-end torque issues in fourstroke spark ignited (SI) engines, due to improvements in engine knock resistance and volumetric efficiency or the reduction of the exhaust gas temperature ${ }^{2,3}$. This is feasible thanks to the use of complex systems such as intake and exhaust variable valve timing (VVT), turbochargers and gasoline direct injection (GDI) systems. Especially the last one plays a fundamental role to harmonise the short-circuit with increasingly stringent pollutant emissions regulations, since GDI allows to ensure that SC gases are fresh air, thus without any direct impact on hydrocarbon emissions.

Although the engine conditions susceptible to get nonnegligible SC are restricted to the area of low engine speed and high load, the each time more extended use of downsized engines in higher segment (thus heavier) passenger cars, are focusing the importance of reducing the emissions under $\mathrm{SC}$ conditions ${ }^{4}$. In addition, emissions in SI engines are strongly dependent on the three way catalyst (TWC) efficiency, making indispensable an accurate fuelto-air ratio (FAR) control ${ }^{5}$. Particularly, according to the TWC operating principle, $\mathrm{HC}, \mathrm{CO}$ and $\mathrm{NO}_{\mathrm{x}}$ emissions can be reduced significantly only very close to stoichiometry, hence the engine should be operated in a narrow window around stoichiometric conditions, hereinafter catalytic window, in order to keep the relative oxygen level within a range even more stringent than that imposed by the catalyst oxygen storage capacity ${ }^{6-9}$.

In this respect, the SC of fresh air to the TWC affects its performance in different ways depending on the incylinder fuel-to-air ratio ${ }^{10}$. One can expect an excess of oxygen in the TWC if the engine is operated at stoichiometric in-cylinder FAR under SC conditions. This oxygen excess will reduce the $\mathrm{NO}_{\mathrm{x}}$ conversion efficiency. On the contrary, keeping a rich in-cylinder FAR will lead to the simultaneous availability of oxygen and fuel at the TWC then increasing its exothermic. Despite this operation can have positive effects, such as the increase in the $\mathrm{NO}_{\mathrm{x}}$ conversion efficiency of the TWC and the reduction of

\footnotetext{
${ }^{1}$ CMT-Motores Térmicos, Universitat Politècnica de València, Valencia, Spain

${ }^{2}$ PSA Peugeot Citroën, La Garenne-Colombes, France
}

Corresponding author:

Marcelo REAL, Camino de Vera, s/n 46022 Valencia, Spain

Email: marreami@mot.upv.es 
the TWC light-off time, it should be controlled to prevent excessive temperatures that may damage the TWC. In addition to the direct effects on the TWC operation, fresh air associated to the SC coming into the exhaust system may affect the FAR control distorting the lambda sensor measurement and precision, acting as a disturbance to the FAR controller, and then resulting in an abnormal operation of the TWC.

Under this scope, the purpose of this paper is to analyse the effect of the fresh air SC on both, the $\lambda$ sensor measurement and TWC operation to finally assess the SC impact on engine emissions. To this aim, a series of experimental tests have been carried out in a stateof-art GDI engine. The paper is organised as follows: The description of the engine, the test cell and the tests performed are presented in Section 2. Then, Section 3 analyses the impact of fresh air pulses coming from the $\mathrm{SC}$ on the $\lambda$ sensor, which is the main sensor to regulate the FAR. The other key element in the pollutant emissions control of SI engines is the TWC, accordingly, Section 4 addresses the experimental results of the tests, assessing the impact of SC on TWC conversion efficiency for the main engine pollutant emissions. Finally, Section 5 outlines the conclusions and most important contributions of the paper.

\section{Tools}

The present paper addresses the effects of fresh air SC from an experimental approach, the following section is aimed to describe the experimental facility and the method used to measure the SC rate, that is, the amount of fresh air that goes directly from intake toward exhaust without taking part in the combustion process, divided by the total mass air flow. Regarding the nomenclature used to refer to the fuel-to-air ratio, hereinafter FAR stands for fuel-to-air equivalence ratio in the sense of physical magnitude, FAR $_{\lambda}$ refers to the measurement of fuel-toair equivalence ratio provided by the $\lambda$ sensor upstream the TWC (when measurements of downstream sensor are reported they are specifically indicated) and $\mathrm{FAR}_{G A}$ refers to the measurement of fuel-to-air equivalence ratio provided by the gas analyser of the test bench also upstream of the TWC.

\subsection{Experimental setup}

All test have been performed with a state-of-art 3-cylinder turbocharged GDI engine whose displacement is 1.2 litres. Table 1 shows the main features of the tested engine.

The original sparks plugs have been replaced by spark plugs with piezoelectric pressure sensors in order to track the in-cylinder pressure evolution. The intake and exhaust lines are also instrumented with average pressure and temperature sensors at the inlet and outlet of each element.
Table 1. Engine setup

\begin{tabular}{ll}
\hline Bore $x$ Stroke & $75 \mathrm{~mm} \times 90.5 \mathrm{~mm}$ \\
Number of cylinder & 3 \\
Total displacement & $1199.9 \mathrm{~cm}^{3}$ \\
Compression ratio & $10.5: 1$ \\
Maximum power & $96 \mathrm{~kW} @ 5500 \mathrm{rpm}$ \\
Maximum torque & $230 \mathrm{Nm} @ 1750-3500 \mathrm{rpm}$
\end{tabular}

The TWC has been especially instrumented in order to measure pressure, temperature, gas composition and FAR with $\lambda$ sensors at the inlet and outlet. The $\lambda$ sensors have been calibrated according to the values provided by the manufacturer, in particular, a Lambda Meter LA4 have been used for each wideband $\lambda$ sensor. The pressure effects on the measurements provided by these sensors have been evaluated previously by using a small vessel with controlled gas composition and pressure. Although the pressure effect is significant at very lean conditions, it has been neglected for the operating conditions evaluated in the present approach, that is, FAR close to stoichiometric and relative pressures below 0.1 bar at catalyst inlet.

The exhaust gas analyser used to quantify the concentration of the different species is an Horiba MEXAONE, properly calibrated with the composition of the fuel to calculate the fuel-to-air ratio according to Brettschneider/Spindt method ${ }^{11}$. But Cambustion NDIR500 Fast $\mathrm{CO} \& \mathrm{CO}_{2}$ and CLD500 Fast $\mathrm{NO}_{\mathrm{x}}$ analysers are also employed to capture the pollutant emission dynamics even to in-cycle level and check the effect of fresh air pulses on the exhaust gas composition. Figure 1 shows a scheme of the engine instrumentation.

The operating point chosen to analyse the SC effect is $1750 \mathrm{rpm}$ and $140 \mathrm{Nm}$, it is representative of the typical low engine speed and high load area where SC is feasible. The valve overlaps imposed in this work are such that the maximum SC rate measured is always below $12 \%$ in order to keep the TWC under its thermal limits. The procedure followed to short-circuit some fresh air towards the exhaust consist of gradually increasing the valve overlap from $-21^{\circ}$ to $80^{\circ}$ crank angle, while the waste gate is progressively opened to keep the engine load constant, without exceeding the turbocharger surge limit nor reaching excessive TWC temperatures. In this way, seven valve overlap levels have been tested as shown in Table 2.

\subsection{Tracer gas method}

There are several well-known methods to experimentally measure the air mass short-circuited in a running engine, like tracer gas or direct sampling among others ${ }^{12-15}$. The inlet tracer gas method has been used in this work, the reason is that this method is easier to implement and allows a better quantification of the average SC ratio 
Table 2. Operating conditions including Valve Overlap, Waste Gate position and averaged SC measurements.

\begin{tabular}{cccc}
\hline $\begin{array}{c}\text { Valve } \\
\text { Overlap }\end{array}$ & $\begin{array}{c}\text { Waste } \\
\text { Gate }\end{array}$ & $\begin{array}{c}\text { Nomenclature } \\
\text { SC rate }\end{array}$ & $\begin{array}{c}\text { Averaged } \\
\text { SC }\end{array}$ \\
\hline$-21^{\circ}$ & 1 & $\mathrm{a}$ & $0.0 \pm 0.26 \%$ \\
\hline $24.9^{\circ}$ & 0.44 & $\mathrm{~b}$ & $0.8 \pm 0.34 \%$ \\
\hline $37.6^{\circ}$ & 0.43 & $\mathrm{c}$ & $1.9 \pm 0.37 \%$ \\
\hline $50.2^{\circ}$ & 0.405 & $\mathrm{~d}$ & $3.7 \pm 0.42 \%$ \\
\hline $59.9^{\circ}$ & 0.39 & $\mathrm{e}$ & $5.6 \pm 0.52 \%$ \\
\hline $69.6^{\circ}$ & 0.375 & $\mathrm{f}$ & $7.5 \pm 0.34 \%$ \\
\hline $80.1^{\circ}$ & 0.36 & $\mathrm{~g}$ & $9.5 \pm 0.66 \%$ \\
\hline
\end{tabular}

for a multi-cylinder GDI engine than the direct sampling method, which would require many in-cycle gas samples for evaluating the cyclic dispersion of the engine and the differences between cylinders.

The tracer gas method is based on the following premises to obtain a reliable measurement ${ }^{16,17}$ :

- The tracer gas is perfectly mixed with the fresh air at the intake manifold.

- The tracer gas has a negligible impact on the normal engine operation.

- The tracer gas trapped into the cylinder burns totally.

- The tracer gas scavenged towards the exhaust is chemically stable and does not react with the fresh air.

- The tracer gas can be accurately measured at both intake and exhaust.

To deal with the assumptions stated before, methane has been chosen as tracer gas in this work. It is injected in small concentrations, specifically $1200 \mathrm{ppm}$ in order to not disturb the normal engine operation, which is always working with methane concentrations below $0.15 \%$ at the inlet manifold. The methane is injected at the inlet of the charge air cooler (CAC), to ensure a perfect mixing with the fresh air. Furthermore, it can be properly measured with the Horiba Mexa One available in the test bench, this analyser separates the sample gas into two different flows to measure hydrocarbons by means of a selective combustion method. On the one hand, a heated flame ionization detector (HFID) provides the total hydrocarbons (THC) measurement, while in parallel, a non-methane cutter (NMC) followed by another FID allows to measure only the methane concentration of the sample. Finally, nonmethane hydrocarbons (NMHC) are calculated by using the two previous measurements, THC and $\mathrm{CH}_{4}$. The NMC is a catalyst that selectively oxidizes all hydrocarbons except $\mathrm{CH}_{4}$ with an oxidation efficiency above $95 \%$ according to manufacturer specifications. The selectivity of the NMC is based on catalyst temperature, exploiting the fact that $\mathrm{CH}_{4}$ is more difficult to burn than other hydrocarbons. This method allows to keep low enough uncertainty levels

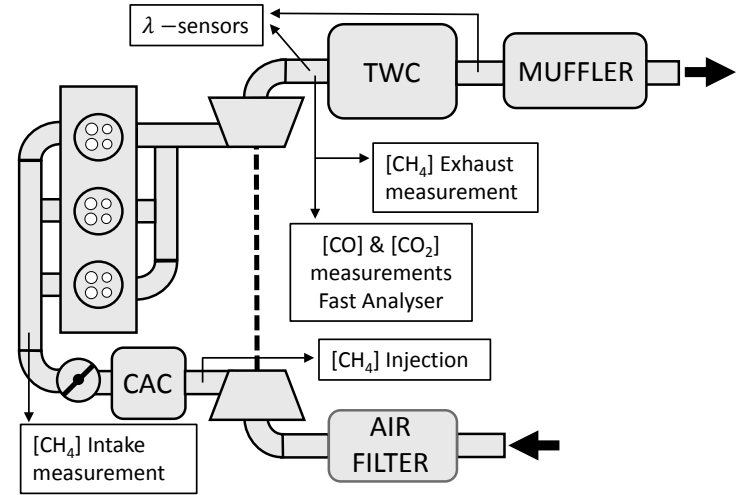

Figure 1. Engine instrumentation diagram.

for methane measurement in the present application, since cross correlations between $\mathrm{CH}_{4}$ and other $\mathrm{HC}$ are avoided. Regarding third and fourth assumptions, it is almost impossible to check whether they are totally fulfilled. If there is not a complete combustion of the tracer gas trapped into the cylinder, the method will overestimate the actual SC. On the contrary, if the tracer gas reacts along the exhaust line, the proposed method will underestimate the SC. In this sense, even if they are not completely fulfilled, their effects would reciprocally cancel ${ }^{18}$.

In particular, the procedure carried out for SC measurement at steady state conditions in this study has been the following:

- $\mathrm{CH}_{4}$ measurement at the TWC inlet, without $\mathrm{CH}_{4}$ injection

- $\mathrm{CH}_{4}$ measurement at the intake manifold, without $\mathrm{CH}_{4}$ injection

- $\mathrm{CH}_{4}$ measurement at the intake manifold, with $\mathrm{CH}_{4}$ injection

- $\mathrm{CH}_{4}$ measurement at the TWC inlet, with $\mathrm{CH}_{4}$ injection

Since there is a single methane analyser available in the experimental facility and intake and exhaust methane concentrations cannot be simultaneously measured, the previous steps have been done sequentially. Thereby, the obtained SC is an averaged value. This fact imposes some limitations as the inability to measure cycle to cycle variations, although in any case, a faster methane analyser than that available would be necessary to capture the incycle pulses.

From the methane measurements, $\mathrm{SC}$ is calculated as follows:

$$
S C=\frac{\left(\left[\mathrm{CH}_{4}\right]_{w / \text { inj }}-\left[\mathrm{CH}_{4}\right]_{w / o \text { inj }}\right)^{e x h}}{\left(\left[\mathrm{CH}_{4}\right]_{w / \text { inj }}-\left[\mathrm{CH}_{4}\right]_{w / o \text { inj }}\right)^{i n t}}
$$




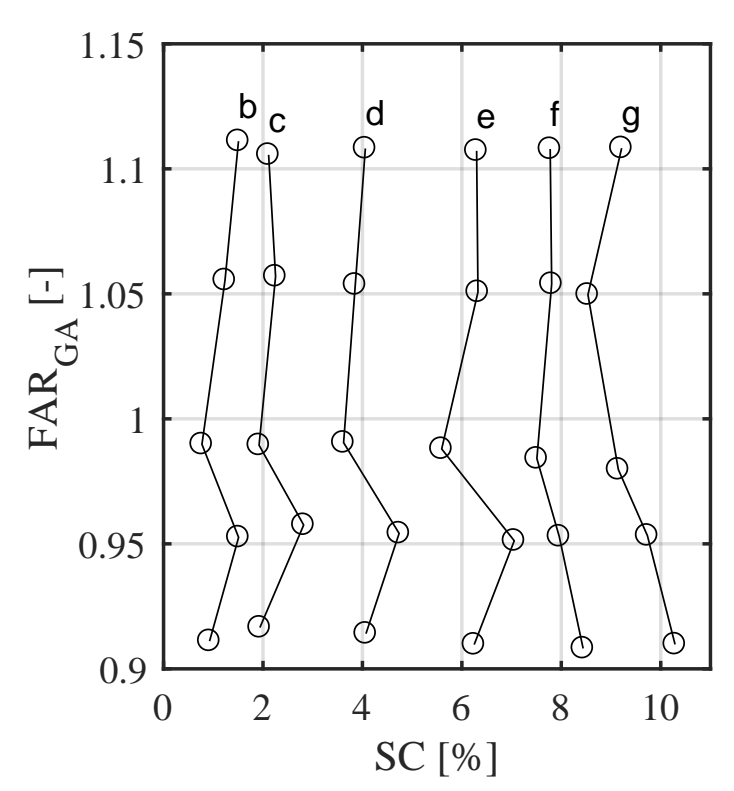

Figure 2. Short-circuit measurement.

where the term $\mathrm{CH}_{4}$ refers to the methane concentration, indexes $w / i n j_{j}$ and $w / o$ inj represent tests with and without methane injection respectively and the indexes int and exh represent engine intake and exhaust manifolds. The SC rates shown in table 2 have been calculated by using this methodology, particularly, they are averaged values of different experimental measurements carried out for each position of both actuators, valve overlap and waste gate.

Figure 2 shows the correlation between the SC measured and valve overlap imposed for 5 different FAR levels, SC ranges from 0 up to around $9.5 \%$ when valve overlap is swept from levels "a" to "g". Besides the dispersion of the tracer gas method, it is considered accurate enough for the present approach, since it allows to quantify experimentally the different SC rates that corresponds to each valve overlap. Note that in the previous results there is not a clear influence of $\mathrm{FAR}_{G A}$ on the SC. In this sense, it can be considered that the SC depends only on the VVT position.

\section{Short-circuit effect on lambda sensor}

Despite the exhaust gas analyser is provided with the composition of the fuel to calculate the fuel-to-air ratio according to Brettschneider/Spindt method ${ }^{11}$, some discrepancy may be expected due to the fact that two different sensors are used to measure the same variable. Figure 3 shows $\mathrm{FAR}_{\lambda}$ upstream and downstream of the TWC against $\mathrm{FAR}_{G A}$ upstream for a wide FAR range, without $\mathrm{SC}$ and at steady state conditions. A bias error almost constant for the present FAR range is provided by the upstream sensor when comparing

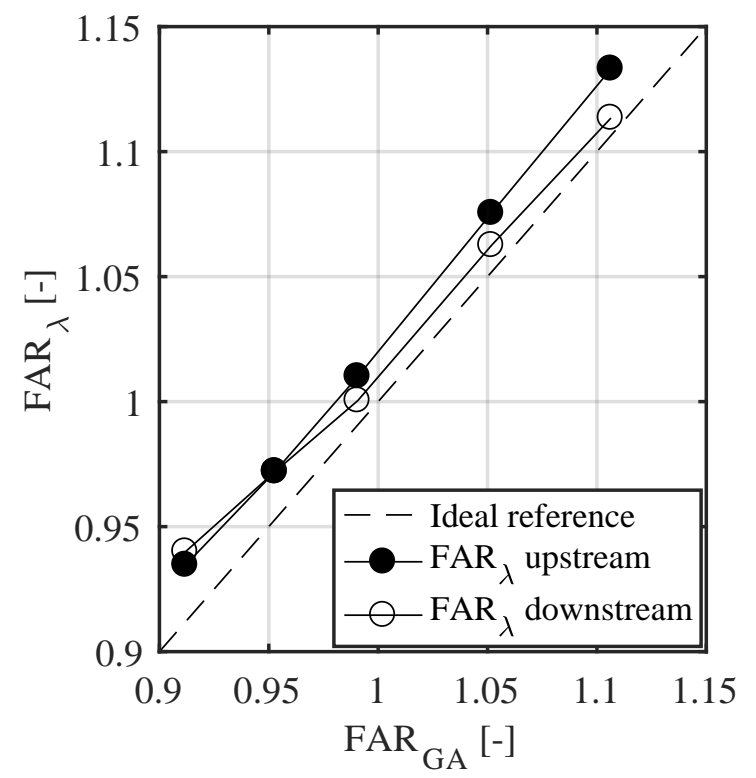

Figure 3. FAR measurements without SC.

with the corresponding measurements provided by the gas analyser, this kind of error is common for wide range $\lambda$ sensors ${ }^{19-21}$. However, as shows Figure 3, the measurements of the downstream wideband $\lambda$ sensor are also affected by changes in gas composition due to the oxidizing/reducing capabilities of the catalyst ${ }^{6,7,22-26}$, that is why only measurements provided by the upstream $\lambda$ sensor are reported in the present paper.

One important difference between both sensors is that, while the upstream $\lambda$ sensor suffers from the exhaust pulsating flow, with continuous changes in gas pressure, temperature and composition that may affect its reading, the volume and the filters before the exhaust gas analyser of the test bench prevent it from suffering these disturbances. In this sense, figure 4 shows the error of the FAR provided by the $\lambda$ sensor $\left(\mathrm{FAR}_{\lambda}\right)$ depending on the SC and the actual FAR measured by the exhaust gas analyser $\left(\mathrm{FAR}_{G A}\right)$. It can be observed how, even in the absence of SC (black circles), there is a bias in the sensor reading of 0.025 that slightly increases with rising $\mathrm{FAR}_{\lambda}$. According to some authors ${ }^{27}$, this bias is due to non-equilibrium of the exhaust gas composition in the TWC inlet. In any case, this non-linearity in the relation between the actual FAR and that provided by the sensor will lead to an increment in the sensor bias as SC increases since the rich-lean FAR pulsations increase. In fact, even though the $\mathrm{FAR}_{\lambda}$ provided by the $\lambda$ sensor is identical for those points which are sharing the same solid line in figure 4, as SC rises their progressive enleanment is evident according to $\mathrm{FAR}_{G A}$. Particularly, this effect could be due to the $\mathrm{CO}$ correlation 


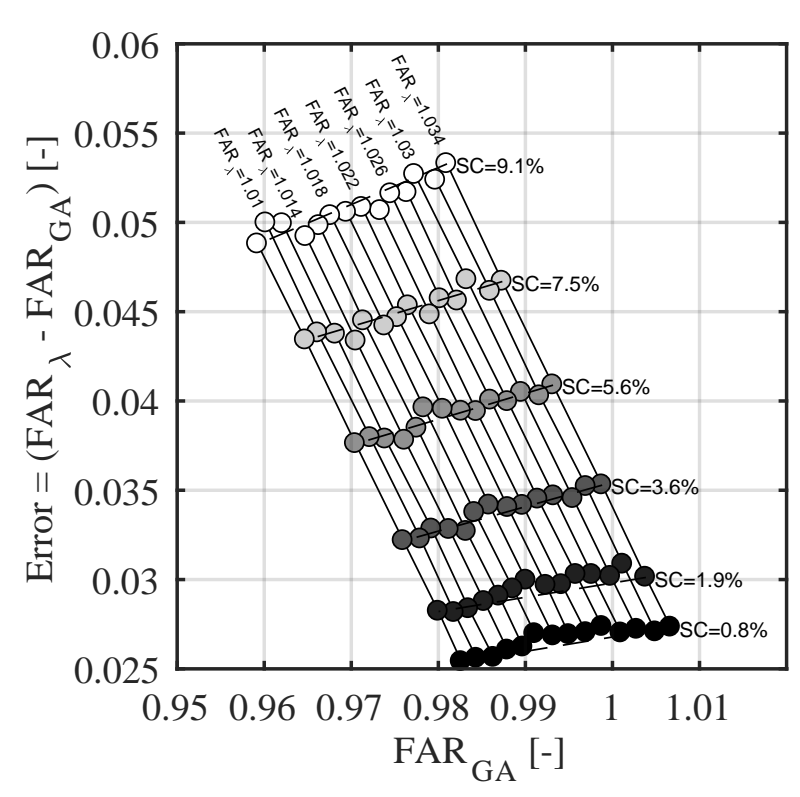

Figure 4. $\mathrm{SC}$ effect on the error between the $\mathrm{FAR}_{\lambda}$ provided by the $\lambda$ sensor and the actual FAR $\mathrm{FA}_{G}$ value provided by the exhaust gas analyser. Solid black lines join points with same $\mathrm{FAR}_{\lambda}$.

with the wide range $\lambda$ sensor $^{23}$, because of the strong $\mathrm{CO}$ increase with SC (Section 4).

In addition to the non-linearity of the $\lambda$ sensor signal with FAR, some authors suggest that the dynamic response of the narrowband $\lambda$ sensor to FAR steps suffers from asymmetry ${ }^{22}$. This effect may also increase the bias in the wideband $\lambda$ sensor signal with $\mathrm{SC}$ as a consequence of the pulsating flow. In order to evaluate the effect of exhaust gas pulses on $\lambda$ sensor and its dynamic response, a particular tests in which the FAR has followed a step profile has been carried out at different engine operating conditions. Figure 5 shows the dynamic response of the wideband $\lambda$ sensor characterized as a delay plus a response time (Tau) experimentally measured for both increasing and decreasing FAR steps. One can observe that differences are within the interval defined by the standard deviation, so no significant asymmetry in the sensor dynamic response can be extracted from the experimental results obtained. Those results are in line with those of ${ }^{28}$, pointing out that there is not a significant asymmetry in the dynamic response of wideband $\lambda$ sensors. Regarding the effect of SC, the slight trend that response time shows is compensated with the gradually increase of delays measured, so it is also negligible.
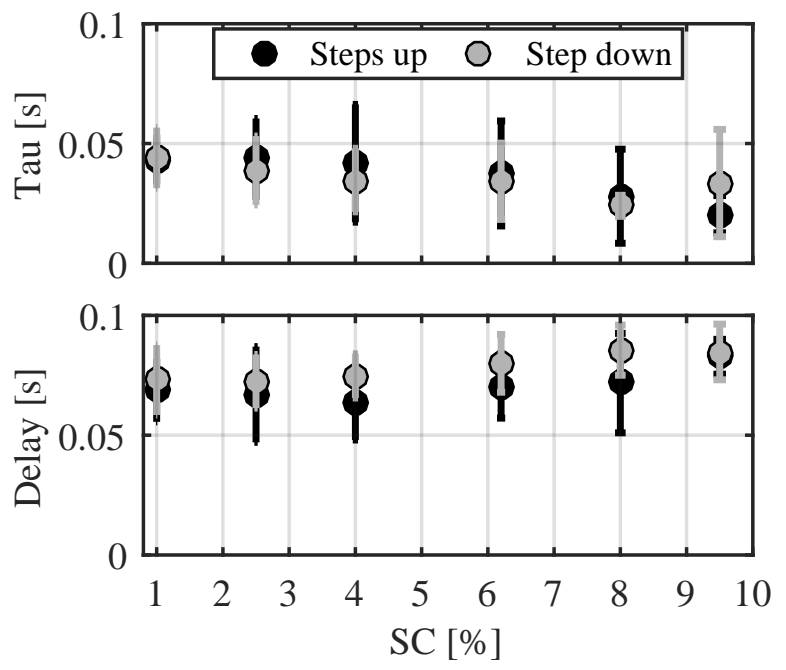

Figure 5. Wideband $\lambda$ sensor response time.

\subsection{In-cycle analysis}

The low response times obtained in previous tests suggest the possibility of using the $\lambda$ sensors to estimate the incycle evolution of the exhaust gas composition. To this end, fast $\mathrm{CO}_{2}$ and $\mathrm{FAR}_{\lambda}$ measurements as well as an one-dimensional wave action model of the engine have been used. Besides $\lambda$ sensor, catalyst inlet has been also instrumented to measure $\mathrm{CO}_{2}$ concentrations with a fast analyser, the crank angle resolution fixed in the acquisition system for both sensors is $0.25^{\circ}$ per sample, that is 42 $\mathrm{kHz}$ at $1750 \mathrm{rpm}$. The sampling rate used is higher than sensors response to avoid filtering the signals during the acquisition process beyond the filtering imposed by the sensor response. For the $\mathrm{CO}_{2}$ analyser, the step response is below $2.5 \mathrm{~ms}$ to reach the $90 \%$ of the final value according to manufacturer data-sheet, thereby actual FAR and $\mathrm{CO}_{2}$ oscillations should be even higher than these provided by the sensor signals.

Since the engine employed is a 3-cylinder, three different SC pulses are expected within an engine cycle. However, the shape of the exhaust manifold (see engine sketch in figure 1), together with the gases transport phenomena as well as the mixing effect along the exhaust line and the filtering effect of the measurement process, result in the $\mathrm{CO}_{2}$ and $\mathrm{FAR}_{\lambda}$ waveforms shown in figure 6. The reader can appreciate three different pulses with different amplitudes in both the $\mathrm{CO}_{2}$ and $\mathrm{FAR}_{\lambda}$ signals.

As the $\mathrm{SC}$ increases, $\mathrm{CO}_{2}$ is progressively diluted and a characteristic waveform appears with rising delays, it is due to an accumulative effect of the fresh air pulses. Although these are produced each $240^{\circ}$ in a different cylinder, each one have to cover paths with different lengths until reaching the TWC inlet due to the exhaust manifold geometry. The behaviour of the in-cycle $\mathrm{FAR}_{\lambda}$ evolution is 

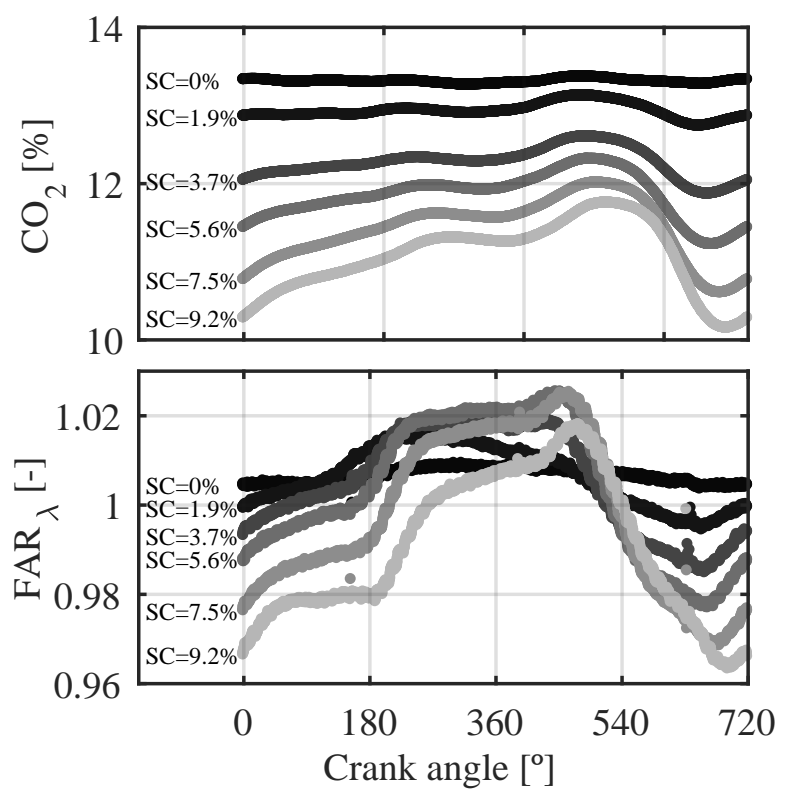

Figure 6. In-cycle averaged $\mathrm{CO}_{2}$ and $\lambda$ waveforms measured for each predefined SC.

alike, a characteristic waveform similar to that of the $\mathrm{CO}_{2}$ appearing when $\mathrm{SC}$ increases. However, the mean value of the $\mathrm{FAR}_{\lambda}$ signal remains constant independently of the SC due to its closed loop control.

The experimental test carried out has been also simulated with a wave action model, imposing exactly the same operating point and valve overlaps. Figures 7 and 8 show the modelled in-cycle evolution for $\mathrm{CO}_{2}$ concentration and FAR respectively at several points along the exhaust line, from exhaust pipes to TWC inlet.

On each exhaust pipe (second plot from the top in figure 7), there is a plateau with high $\mathrm{CO}_{2}$ concentration during the exhaust stroke of its respective cylinder and then a sudden decrease appears during valve overlap when fresh air goes through the pipe. Finally, when the exhaust valves close, the $\mathrm{CO}_{2}$ concentration keeps at low level until the next stroke. In the exhaust manifold (third plot in figures 7 and 8) the main difference is that the mass flow is hardly ever zero, given that fresh air pulses are followed by exhaust gases from next cylinder according to the firing order and there is some diffusion of gases in the manifold. Additionally, as a consequence of the manifold geometry, the path length from each exhaust pipe to the turbine inlet is different, so it is reflected by the amplitude and duration of $\mathrm{CO}_{2}$ and FAR pulses. As the measurement point goes far from the cylinders, the mixing effect is stronger, thus pulses are progressively smaller and delayed as can be observed in the third plot of both figures.

Finally, a first order linear model, which intends to simulate the filtering effect of sensors, is applied to

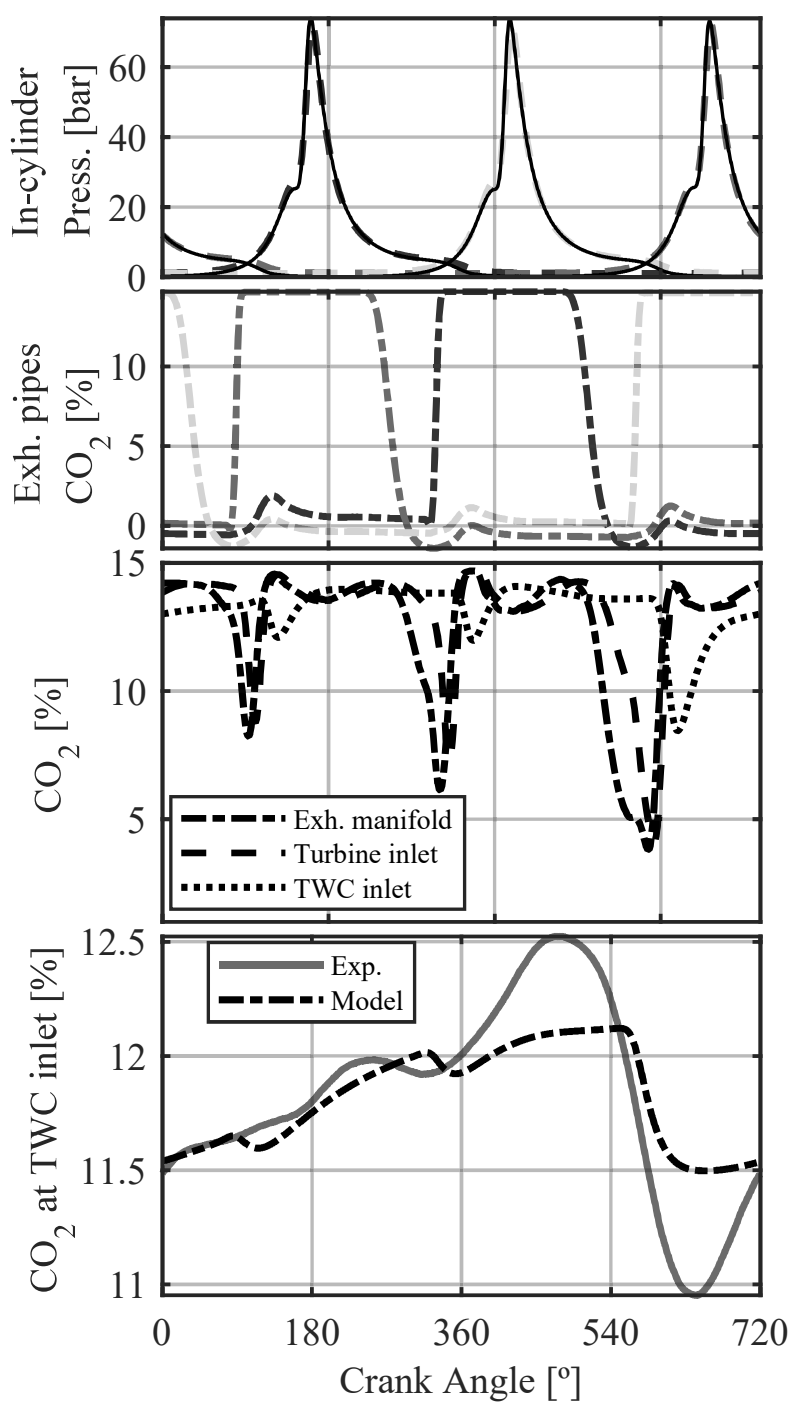

Figure 7. $S C=9.5 \%$ First row: In-cycle pressures, modelled (dashed) versus experimental (solid); Second row: Modelled in-cycle evolution for $\mathrm{CO}_{2}$ concentration at exhaust pipes; Third row: Modelled in-cycle evolution for $\mathrm{CO}_{2}$ concentration at several points along the exhaust line; Fourth row: $\mathrm{CO}_{2}$ concentration measurement, modelled (dashed) versus experimental (solid).

the instantaneous signals $\left(\mathrm{CO}_{2}\right.$ concentration and FAR $)$ modelled at TWC inlet, in order to compare them with the experimental measurements at the same point. Even though the model is not perfectly fitted and the filtering effect of the experimental measurement could not be exactly a first order, modelled and measured fit quite good as it is shown in the bottom plot of figures 7 and 8 . In this sense, in-cycle evolutions of $\mathrm{CO}_{2}$ and $\mathrm{FAR}_{\lambda}$ shown in figure 6 are justified by the fresh air pulses coming from the SC and the sensor dynamic response. Note that despite the sensor limitations, 


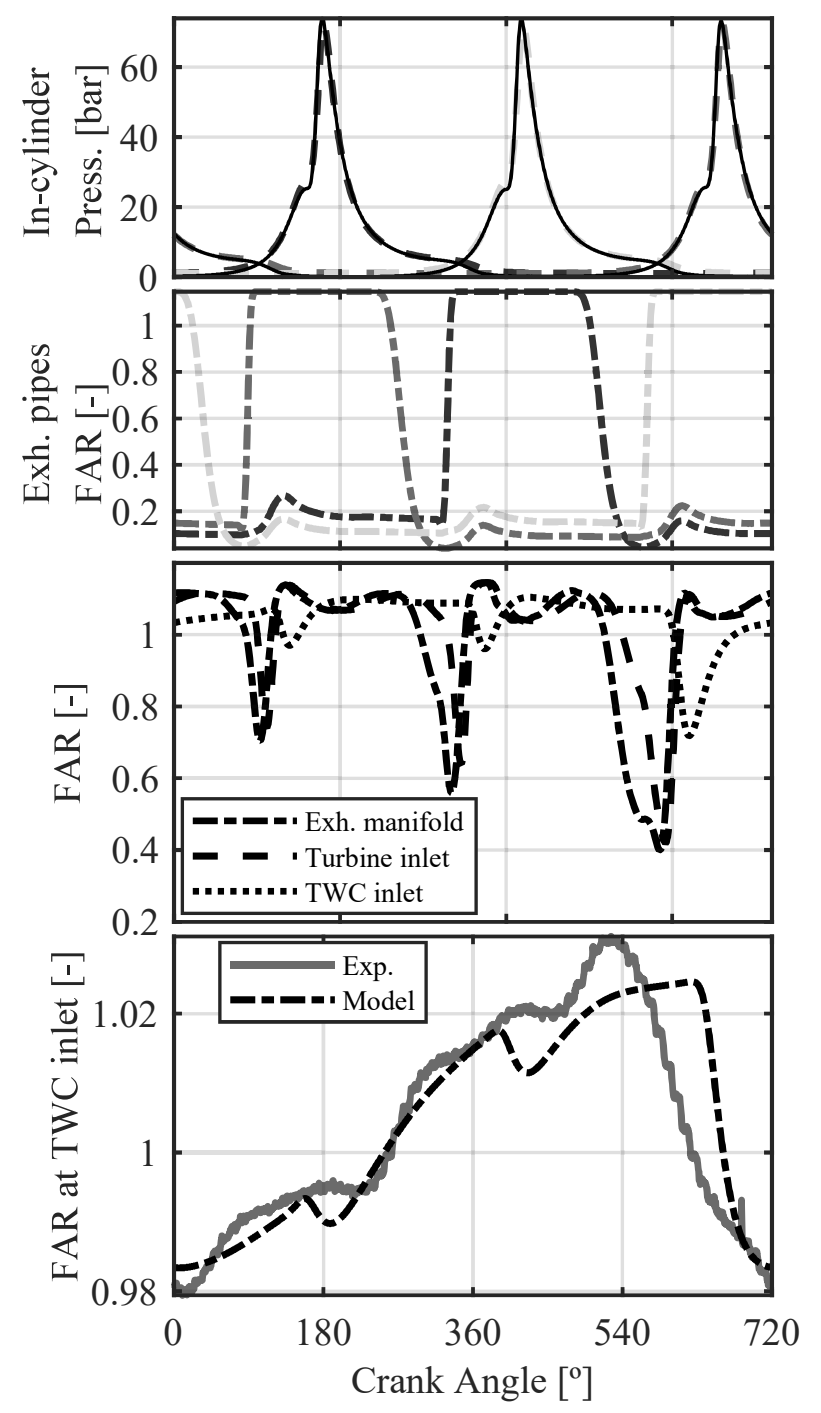

Figure 8. $S C=9.5 \%$ First row: In-cycle pressures, modelled (dashed) versus experimental (solid); Second row: Modelled in-cycle evolution for FAR at exhaust pipes; Third row:

Modelled in-cycle evolution for FAR at several points along the exhaust line; Fourth row: $\mathrm{FAR}_{\lambda}$ measurement, modelled (dashed) versus experimental (solid).

it is sensitive to $\mathrm{SC}$, since the pulses amplitude is clearly affected by SC.

\section{Short-circuit effect on three-way catalyst behaviour}

Since the $\lambda$ sensor is the fundamental element in the FAR control of SI engines, the impact of the SC on the $\lambda$ sensor leads to variations in the operating FAR that involve modifications in the expected engine performance and emissions. Moreover, it should be noted that since the engine control is aimed to keep the $\mathrm{FAR}_{\lambda}$ provided by the $\lambda$ sensor around the desired value, the oxygen content that is actually controlled is that at the sensor location, i.e at the TWC inlet. Therefore, even in the case of a perfect correction of the SC effect on the $\lambda$ sensor, the $\mathrm{SC}$ will involve some modification of the in-cylinder gas composition. A simple mass balance in the cylinders leads to the following relation between in-cylinder and exhaust gas composition in terms of FAR:

$$
F A R_{c y l}=F A R \frac{1}{1-S C}
$$

where $\mathrm{FAR}_{c y l}$ represent the fuel to air ratio at the cylinder and the term FAR refers to the fuel to air ratio at the exhaust (before TWC). One can observe that, given a constant exhaust FAR, a SC increase involves a rise at the in-cylinder FAR. Since the engine raw emissions are driven by the incylinder FAR, an important effect of the SC on the exhaust gas composition at TWC inlet is expected.

In this sense Figure 9 shows the sensitivity of the exhaust gas composition to the $\mathrm{SC}$ and the $\mathrm{FAR}_{G A}$. Obviously, for a given SC level, the higher the FAR, the higher the $\mathrm{CO}$ emissions due to incomplete combustion. However, the most remarkable idea of Figure 9 is that for a given exhaust $\mathrm{FAR}_{G A}$, a noticeable increase in $\mathrm{CO}$ emissions is obtained when the $\mathrm{SC}$ rises, i.e. for a $\mathrm{FAR}_{G A}$ of 0.98 , the $\mathrm{CO}$ emissions increase up to 5 times when the $\mathrm{SC}$ increases from 0 to $9.5 \%$. The reason for such an increase is that the in-cylinder FAR should rise to keep constant exhaust FAR when the engine operates with higher levels of SC. Conversely, both exhaust FAR and SC increases contribute to a reduction in the $\mathrm{NO}_{\mathrm{x}}$ concentration of raw engine exhaust gases, since both entail an increase in the in-cylinder FAR.

As a consequence of the in-cylinder FAR being the prime driver of the combustion process and therefore also of the engine raw emissions, Figure 10 displays how $\mathrm{CO}$ and $\mathrm{NO}_{\mathrm{x}}$ emissions collapse in a line when all the measurements are represented against the in-cylinder FAR $\left(\mathrm{FAR}_{c y l, G A}\right)$ calculated through $\mathrm{FAR}_{G A}$ at the exhaust, of course within the measurement accuracy margin and neglecting the dilution effect of SC on the exhaust mass flow. Some misalignment of the results obtained with $S C_{a}$ tests can be observed, this can be justified by the fact that at these conditions the engine operates with a negative valve overlap and therefore, the quality of the engine combustion may be worse, then increasing the residuals and accordingly contributing to higher $\mathrm{CO}$ and lower $\mathrm{NO}_{\mathrm{x}}$ emissions than the general trend.

Once the effect of SC on engine raw emissions has been discussed, it is easier to understand how the emissions downstream the TWC are also affected by SC as shows Figure 11. Given a $\mathrm{FAR}_{G A}$, the SC involves an increase 


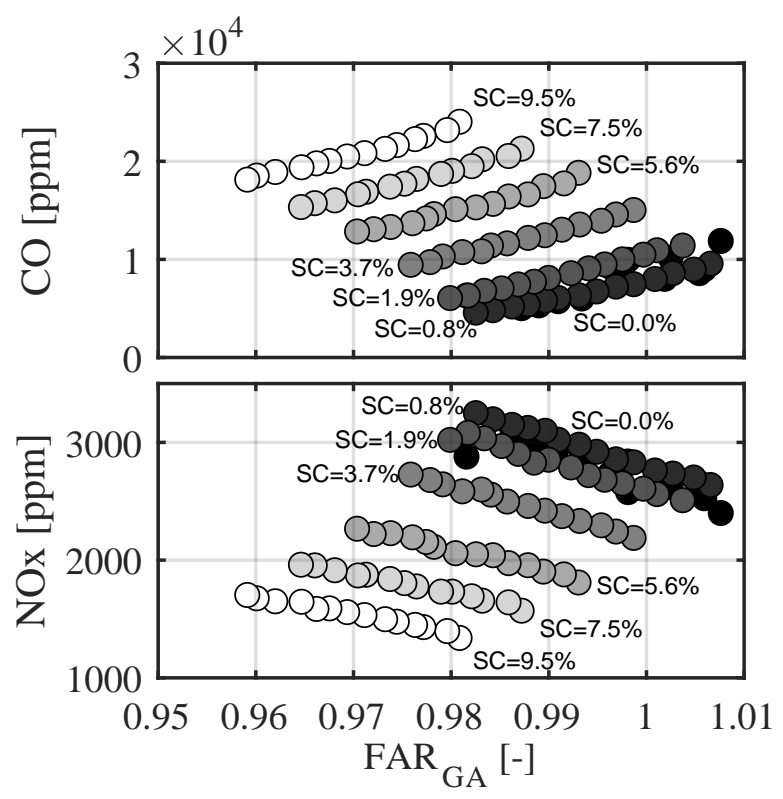

Figure 9. Effect of $\mathrm{FAR}_{G A}$ and $\mathrm{SC}$ on engine raw emissions upstream TWC. Top: $\mathrm{CO}$ emissions; Bottom: $\mathrm{NO}_{\mathrm{x}}$ emissions.
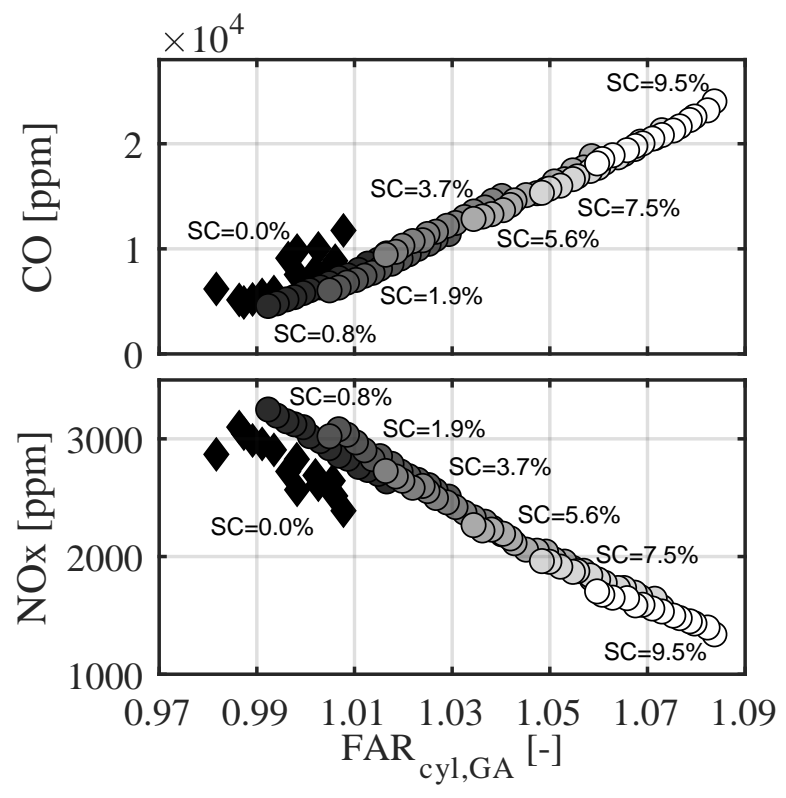

Figure 10. Effect of in-cylinder FAR $\left(\mathrm{FAR}_{c y l, G A}\right)$ and $\mathrm{SC}$ on engine emissions upstream the TWC. Top: CO emissions; Bottom: $\mathrm{NO}_{\mathrm{x}}$ emissions.

in the $\mathrm{CO}$ emissions and a reduction of $\mathrm{NO}_{\mathrm{x}}$. The effect on $\mathrm{CO}$ emissions is more evident from stoichiometric to rich conditions (due to the lower efficiency of the TWC) while the effect on $\mathrm{NO}_{\mathrm{x}}$ becomes more apparent at lean conditions (because of the same reason). In any case, SC displaces the TWC window towards leaner conditions. According to results shown in Figure 9, $\mathrm{NO}_{\mathrm{x}}$ decreases with $\mathrm{SC}$, while
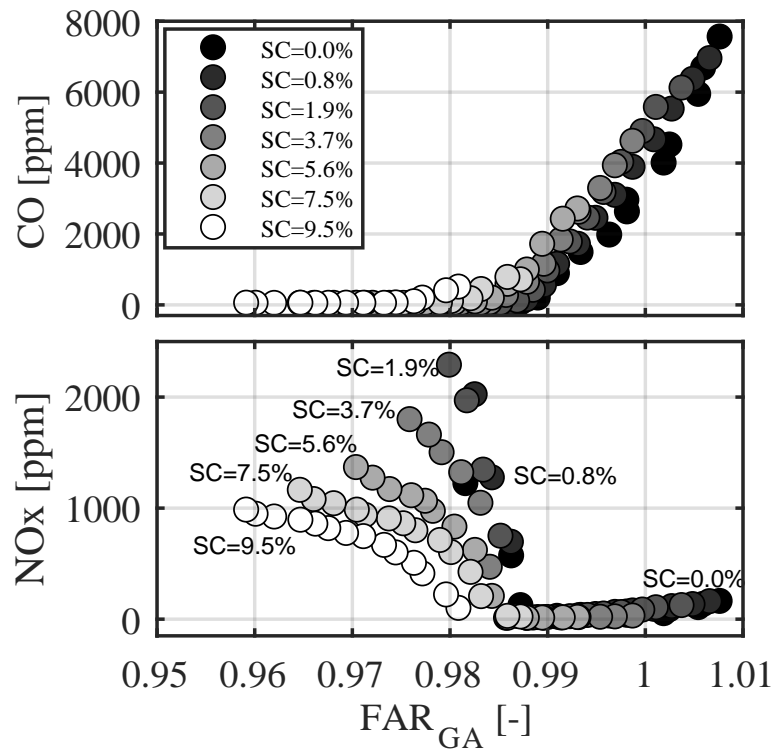

Figure 11. Effect of $\mathrm{FAR}_{G A}$ and $\mathrm{SC}$ on engine emissions downstream the TWC. Top: $\mathrm{CO}$ emissions; Bottom: $\mathrm{NO}_{\mathrm{x}}$ emissions.

the opposite trend is observed for $\mathrm{CO}$, both facts contribute to shift the TWC window to leaner $\mathrm{FAR}_{G A}$.

On the other hand, the TWC itself is affected by SC. The fresh air pulses coming from the SC and the larger peaks in $\mathrm{CO}$ concentrations coming from the higher incylinder FAR conditions involve a clear loss of efficiency. The TWC efficiency in terms of $\mathrm{CO}$ oxidation and $\mathrm{NO}_{\mathrm{x}}$ reduction is represented against $\mathrm{FAR}_{G A}$ and $\mathrm{SC}$ in Figure 12. Experimental results show that the $\mathrm{CO}$ oxidation efficiency around stoichiometric conditions is harmed by $\mathrm{SC}$, the increase in $\mathrm{HC}$ and $\mathrm{CO}$ emissions at the TWC inlet due to rich in-cylinder FAR is not compensated by the availability of fresh air coming from the SC. On the contrary, results point out some improvement in the $\mathrm{NO}_{\mathrm{x}}$ reduction capabilities of the TWC from lean to stoichiometric conditions. The reason for that may be the pulses with high $\mathrm{CO}$ (and other reducing species such as $\mathrm{H}_{2}$ ) that allow to reduce $\mathrm{NO}_{\mathrm{x}}$ even with global FAR levels below stoichiometric.

The combination of the impact of SC on engine raw emissions and TWC efficiency leads to a general deterioration of the $\mathrm{CO}$ and $\mathrm{NO}_{\mathrm{x}}$ tradeoff as pointed out in Figure 13. It can be clearly observed that the increase in $\mathrm{SC}$ involves some penalty on emissions since the tradeoff is shifted from the origin towards higher $\mathrm{CO}$ and $\mathrm{NO}_{\mathrm{x}}$ emissions. In line with previous results, contour lines of constant $\mathrm{FAR}_{G A}$ show that the increase in SC involves, in general, a reduction in $\mathrm{NO}_{\mathrm{x}}$ emissions at the expense of an increase in $\mathrm{CO}$. In this sense, given the emissions in the 


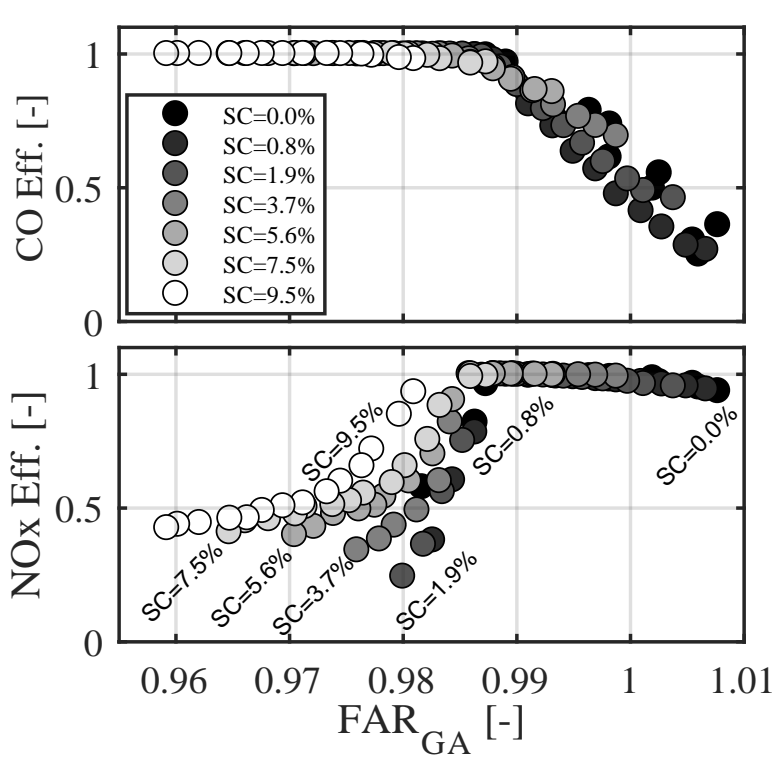

Figure 12. Effect of $\mathrm{FAR}_{G A}$ and SC on TWC efficiency. Top: $\mathrm{CO}$ oxidation efficiency; Bottom: $\mathrm{NO}_{\mathrm{x}}$ reduction efficiency.

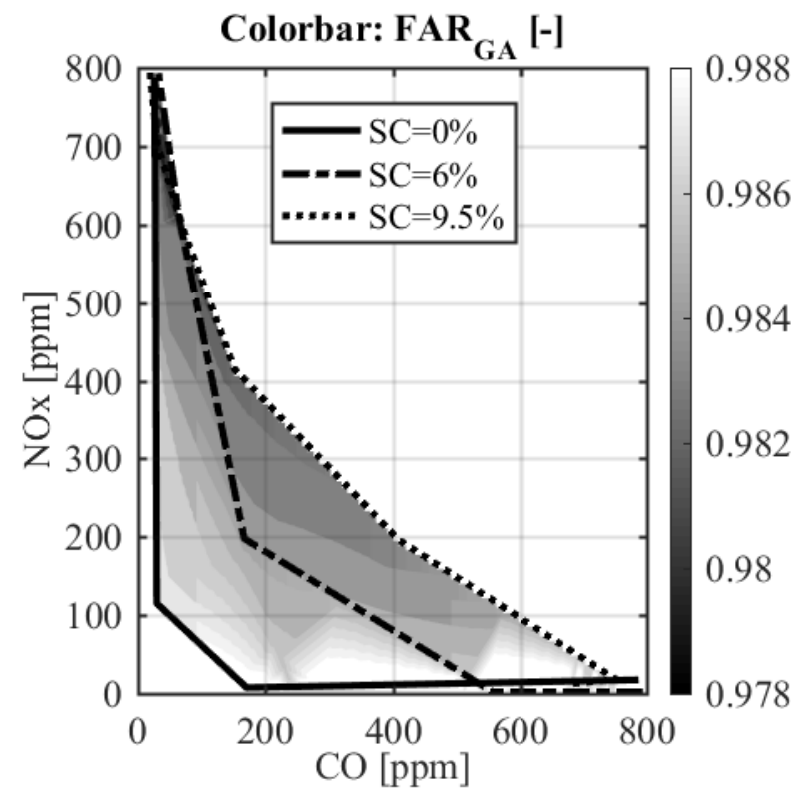

Figure 13. Actual FAR $\left(\mathrm{FAR}_{G A}\right)$ in the map CO-NO $\mathrm{x}_{\mathrm{x}}$.

reference operating point without $\mathrm{SC}\left(\mathrm{FAR}_{G A}=0.988\right)$ and going toward a $\mathrm{SC}$ of $9.5 \%$ at constant $\mathrm{FA}_{G A}$, it will involve an increase in $\mathrm{CO}$ concentration from 100 to $800 \mathrm{ppm}$ at the expense of a small reduction in $\mathrm{NO}_{\mathrm{x}}$ emissions from 80 to 20 ppm.

Note that while previous figure shows contour-lines of actual FAR $\left(\mathrm{FAR}_{G A}\right)$, the effect of the SC on the $\lambda$ sensor prevents the engine to operate at constant $\mathrm{FAR}_{G A}$ when subjected to SC. In this sense, Figure 14 shows the contours

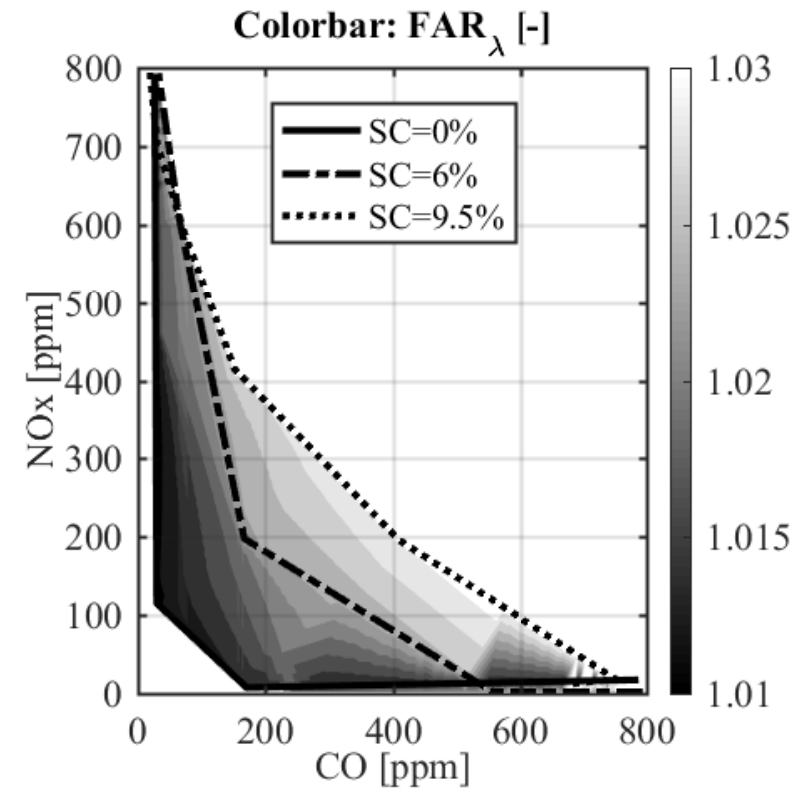

Figure 14. $\mathrm{FAR}_{\lambda}$ provided by the $\lambda$ sensor in the map CO-NO ${ }_{x}$.

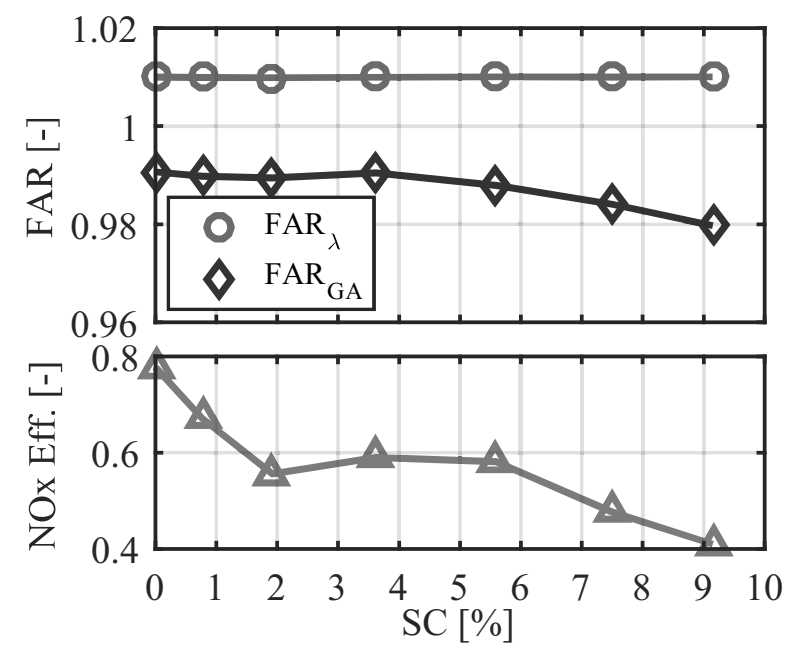

Figure 15. Actual FAR $\mathrm{FA}_{\text {A }}$ and TWC efficiency in terms of $\mathrm{NO}_{\mathrm{x}}$ reduction as SC increases with standard FAR control strategy.

of constant $\mathrm{FAR}_{\lambda}$ in the tradeoff $\mathrm{CO}-\mathrm{NO}_{\mathrm{x}}$. One can observe that if the $\mathrm{FAR}_{\lambda}$ of the engine operating without $\mathrm{SC}$, i.e. 1.01 , is maintained, when $\mathrm{SC}$ is applied an important shift on $\mathrm{NO}_{\mathrm{x}}$ will appear, passing from 80 to $800 \mathrm{ppm}$ if the $\mathrm{SC}$ exceeds a $6 \%$.

As a summary, the result of increasing the SC at constant $\mathrm{FAR}_{\lambda}$ provided by the $\lambda$ sensor in both, the actual FAR $\left(\mathrm{FAR}_{G A}\right)$ and the TWC efficiency (in terms of $\mathrm{NO}_{\mathrm{x}}$ reduction), is shown in Figure 15, pointing out a noticeable impact on efficiency reduction when SC increases. 
Previous results lead to the conclusion that, while emissions at low engine speed and high torque become important, emissions criteria should be included in the SC level calibration. Or conversely, that both the effect of SC on the $\lambda$ sensor and TWC operation should be taken into account when designing the FAR control strategy of the engine.

\section{Conclusions}

The widespread use of downsizing have highlighted the importance of engine emissions under SC conditions, which is a subject barely addressed in the literature. In this sense, the present paper deals with the impact of SC on the emissions of a state-of-art SI engine from an experimental perspective. In particular, the effect of the SC on the engine raw emissions and the TWC outlet emissions has been analysed and the impact on the main exhaust elements, i.e. $\lambda$ sensor measurement and TWC efficiency has been addressed.

Experimental results show that the SC process has a nonnegligible impact on the in-cycle dynamics of exhaust gases composition. Fresh air pulses short-circuited, in addition to the different exhaust air path of each cylinder result in a characteristic $\lambda$ waveform, that due to its high frequency as well as to its amplitude dependence on short-circuit rate reached, suppose an issue for the accurate fuel to air ratio measurement. The sensor bias, which increases with FAR together with the rich and lean pulses due to short-circuit, lead to $\lambda$ sensors to overestimate the real fuel to air ratio at the TWC inlet. This overestimation involves an actual lean FAR $_{G A}$ when the engine controls the $\mathrm{FAR}_{\lambda}$ signal provided by the $\lambda$ sensor without considering SC. This behaviour has a final impact on $\mathrm{NO}_{\mathrm{x}}$ emissions that are considerable increased.

Regarding the TWC operation, the pulses with high $\mathrm{CO}$ and other reducing species coming from the rich incylinder FAR required to operate the TWC at stoichiometric under $\mathrm{SC}$ conditions, involve an increase in $\mathrm{NO}_{\mathrm{x}}$ reduction efficiency and a penalty in the $\mathrm{CO}$ oxidation capabilities of the TWC. In addition to this, the non-linearity of the combustion process itself, involves higher productions of $\mathrm{CO}$ due to rich in-cylinder FAR. The final result is that when the engine is operated with SC, the sweet-spot of minimum emissions is shifted to lean conditions.

As a conclusion, despite the impact of the SC on the $\lambda$ sensor measurement and the TWC efficiency is somehow opposite, according to the obtained results, they do not cancel each other and the SC should be included in the FAR control strategy, at least from the emissions point of view. This last conclusion, justify the interest of developing on board SC estimation methods that could be used to correct its negative impact on emissions.

\section{Acknowledgements}

The authors acknowledge the support of Spanish Ministerio de Economía, Industria y Competitividad through project TRA2016-78717-R.

\section{References}

1. Heywood J. Internal combustion engines fundamentals, 2000.

2. Pagot A, Duparchy A, Gautrot X et al. Combustion approach for downsizing: the ifp concept. Oil \& gas science and technology 2006; 61(1): 139-153.

3. Ranini A and Monnier G. Turbocharging a gasoline direct injection engine. Technical Report No. 2001-01-0736, SAE Technical Paper, 2001.

4. Martin S, Beidl C and Mueller R. Responsiveness of a 30 bar bmep 3-cylinder engine: Opportunities and limits of turbocharged downsizing. Technical Report No. 2014-011646, SAE Technical Paper, 2014.

5. Shafai E, Roduner $\mathrm{C}$ and Geering HP. Indirect adaptive control of a three-way catalyst. Technical Report No. 961038, SAE Technical Paper, 1996.

6. Auckenthaler TS, Onder CH, Geering HP et al. Modeling of a three-way catalytic converter with respect to fast transients of $\lambda$-sensor relevant exhaust gas components. Industrial \& engineering chemistry research 2004; 43(16): 4780-4788.

7. Auckenthaler TS, Onder $\mathrm{CH}$ and Geering HP. Online estimation of the oxygen storage level of a three-way catalyst. Technical Report No. 2004-01-0525, SAE Technical Paper, 2004.

8. Balenovic M, Backx A and Hoebink J. On a model-based control of a three-way catalytic converter. Technical Report No. 2001-01-0937, SAE Technical Paper, 2001.

9. Balenovic M, Backx T and De Bie T. Development of a model-based controller for a three-way catalytic converter. Technical Report No. 2002-01-0475, SAE Technical Paper, 2002.

10. Pischinger S. Current and future challenges for automotive catalysis: Engine technology trends and their impact. Topics in Catalysis 2016; : 1-11.

11. Silvis WM. Method and system for determining air/fuel ratio of an engine's combustion process from its exhaust emissions, 2001. US Patent 6,209,385.

12. Schweitzer P. Scavenging of two-stroke cycle Diesel engines. Macmillan Co., 1949.

13. Taylor CF. The Internal-combustion Engine in Theory and Practice: Combustion, fuels, materials, design, volume 2. MIT press, 1985.

14. Ferrari G and Esculapio S. Internal Combustion Engines. Società Editrice Esculapio, 2014. ISBN 9788874888054.

15. Gupta H. Fundamentals of internal combustion engines. PHI Learning, 2012. ISBN 9788120346802.

16. Olsen DB. Experimental and theoretical development of a tracer gas method for measuring trapping efficiency in 
internal combustion engines. $\mathrm{PhD}$ Thesis, Colorado State University, 1999.

17. Olsen DB, Hutcherson GC, Willson BD et al. Development of the tracer gas method for large bore natural gas engines. part $\mathrm{i}$ : Method validation. Journal of engineering for gas turbines and power 2002; 124(3): 678-685.

18. McGough MG and Fanick ER. Experimental investigation of the scavenging performance of a two-stroke opposed-piston diesel tank engine. Technical Report No. 2004-01-1591, SAE Technical Paper, 2004.

19. Fiengo G, Cook J and Grizzle J. Experimental results on dual uego active catalyst control. In First IFAC Symposium on Advances in Automotive Control, Salerno Italy.

20. Yildiz Y, Annaswamy AM, Yanakiev D et al. Spark ignition engine fuel-to-air ratio control: An adaptive control approach. Control Engineering Practice 2010; 18(12): 1369-1378.

21. Tomforde M, Drewelow W and Schultalbers M. Air-fuel ratio control with respect to oxygen storage dynamics. In Methods and Models in Automation and Robotics (MMAR), 2011 16th International Conference on. IEEE, pp. 242-247.

22. Auckenthaler TS, Onder CH and Geering HP. Modelling of a solid-electrolyte oxygen sensor. Technical Report No. 200201-1293, SAE Technical Paper, 2002.

23. Germann H, Taglaiferri S and Geering HP. Differences in preand post-converter lambda sensor characteristics. Technical Report No. 960335, SAE Technical Paper, 1996.

24. Ingram GA and Surnilla G. On-line oxygen storage capacity estimation of a catalyst. Technical Report No. 2003-01-1000, SAE Technical Paper, 2003.

25. Moos R. Catalysts as sensorsa promising novel approach in automotive exhaust gas aftertreatment. Sensors 2010; 10(7): 6773-6787.

26. Schödel S, Moos R, Votsmeier M et al. Si-engine control with microwave-assisted direct observation of oxygen storage level in three-way catalysts. IEEE Transactions on Control Systems Technology 2014; 22(6): 2346-2353.

27. Fiengo G, Cook JA and Grizzle J. Fore-aft oxygen storage control. In Proceedings of the 2002 American Control Conference (IEEE Cat. No. CH37301), volume 2. IEEE, pp. 1401-1406.

28. Ménil F, Susbielles M, Debéda $\mathrm{H}$ et al. Evidence of a correlation between the non-linearity of chemical sensors and the asymmetry of their response and recovery curves. Sensors and Actuators B: Chemical 2005; 106(1): 407-423. 